\title{
Seasonal and weather factors influencing the annual flight cycle of Prostephanus truncatus (Coleoptera: Bostrichidae) and its predator Teretriosoma nigrescens (Coleoptera: Histeridae) in Benin
}

\author{
C. Borgemeister ${ }^{1}$, W.G. Meikle ${ }^{1}$, D. Scholz ${ }^{1,2}$, \\ C. Adda ${ }^{1}$, P. Degbey ${ }^{1}$ and R.H. Markham ${ }^{1}$ \\ 'International Institute of Tropical Agriculture, Plant Health \\ Management Division, 08 B.P. 0932, Cotonou, Republic of Benin: \\ ${ }^{2}$ Institut für Pflanzenkrankheiten und Pflanzenschutz, Universität \\ Hannover, Herrenhäuser Str. 2, 30419 Hannover, Germany
}

\begin{abstract}
Investigations were carried out in southern Benin on the annual flight cycle and the effects of weather variables on the flight activity of Prostephanus truncatus (Horn) and its natural enemy, Teretriosoma nigrescens Lewis. Two seasonal peaks in flight activity of $P$. truncatus were observed, one between the end of December and the beginning of January and a second one between May and June. Teretriosoma nigrescens showed a single delayed peak in June, approximately six weeks after the major peak of $P$. truncatus. Flight activity of $P$. truncatus was only weakly associated with weather characteristics (standardized regression coefficient for mean daily temperature $b=0.18, t=2.87, P<0.05)$ ), whereas for $T$. nigrescens it was associated with precipitation (standardized regression coefficient for accumulated rainfall during the trapping period $\mathrm{b}=0.38, \mathrm{t}=4.76, P<0.05$ ). The possibility that one of the $P$. truncatus peaks was associated with dispersal from crowded maize stores and the other with the search for natural woody host plants is discussed.
\end{abstract}

\section{Introduction}

Since its accidental introduction into East and West Africa in the late seventies and early eighties, respectively (Dunstan \& Magazini, 1981; Harnisch \& Krall, 1984), the larger grain borer Prostephanus truncatus (Horn) (Coleoptera: Bostrichidae) has become the most serious pest of farm stored maize and cassava in Africa. Native to Mexico and Central America (Markham et al., 1991), the beetle has spread to date to a total of 12 African countries (Hodges, 1994; Adda et al., 1996). In an attempt to use classical biological control, Teretriosoma nigrescens Lewis (Coleoptera: Histeridae), a histerid beetle predator, was identified in Central America as a natural enemy (Haines, 1981; Boeye, 1988). Subsequently the predator was introduced to Africa, and so far has been released in three West African countries, i.e. Togo (Biliwa et al., 1992), Benin (Anon., 1992) and Ghana (Compton \& Ofosu, 1994) and in one East African country, i.e. Kenya
(Giles et al., 1995). Studies to assess the impact of the natural enemy are under way.

Both predator and prey are attracted to an aggregation pheromone produced by males of $P$. truncatus (Hodges et al., 1984), and a synthetic pheromone is currently used for monitoring purposes (Dendy et al., 1989; Rees et al., 1990). Little is known about the annual flight cycle and meteorological effects on the flight cycle of $P$. truncatus and $T$. nigrescens in coastal West Africa. In this paper we describe the annual flight cycle of both insects in southern Benin and investigate the effects of weather on the flight activity of $P$. truncatus and T. nigrescens, using multi-season trapping data from two regions in Benin. The annual flight cycle of the beetles was analysed using trap results from the central part of the Mono province of south-western Benin, because $P$. truncatus spread from Togo to Benin (Anon., 1986), and T. nigrescens was originally released in this province (Anon., 1992). However, the only weather data we obtained for the 
Mono province were precipitation figures. Therefore the trap data recorded on the Benin station of the International Institute of Tropical Agriculture (IITA) in Abomey-Calavi (a suburb of Cotonou) were used for the analysis of the effects of weather on the flight activity of the two insects.

\section{Material and methods}

Eight sticky flight traps (Pherocon II B. Trécé Inc., Salinas, California, USA) baited with the two-component synthetic aggregation pheromone of $P$. truncatus (i.e. $1 \mathrm{mg}$ of Truncall 1 and $1 \mathrm{mg}$ of Truncall 2; AgriSense-BCS, Pontypridd, UK), previously developed by the Natural Resources Institute (NRI) (Dendy et al., 1989), were set up in the central part of the Mono province, a region where $P$. truncatus has been present since 1986 (Anon., 1986) and $T$. nigrescens is continuously recorded in pheromone traps since 1992 (Borgemeister, unpublished data) (fig. 1). The traps were attached to shrubs or trees in a height of $c .1 .5 \mathrm{~m}$. The distance between the different trap sites ranged between 2.5 and $20 \mathrm{~km}$. For all sites the geographic position was determined using a satellite based Global Positioning System (Scout GPS ik, Trimble Navigation Inc., Austin, Texas, USA). The traps and pheromone lures were collected and replaced every seven days, and data were gathered between October 1993 until October 1994 on the annual flight cycle of $P$. truncatus and $T$. nigrescens. The daily rainfall data were kindly provided by the weather station of the Centre d'Action Régionale pour le Développement Rural (CARDER) in Lokossa, Mono province. The accumulated precipitation during the respective trapping periods, i.e. the seven days interval of trapping, were used in the analysis. The distance between the different trap sites and the weather station in Lokossa ranged from 4.5 to $27 \mathrm{~km}$.

Three additional sticky flight traps were distributed on the IITA station in Abomey-Calavi. The traps were attached to trees at a height of $c .1 .5 \mathrm{~m}$. Since the maximum sampling range for $P$. truncatus using pheromone baited flight traps is $340 \mathrm{~m}$ (Farrell, 1990; Farrell \& Key, 1992), the traps were separated by a distance of at least $300 \mathrm{~m}$. Traps and pheromone lures were collected and replaced on a weekly basis. Flight data collected from April 1992 to December 1995 were used in the analysis of meteorological parameters affecting the flight activity of $P$. truncatus. For $T$. nigrescens only the trap catches from January 1994 onwards were used in this study, i.e. when the predator was consistently recorded in the pheromone traps on the IITA station. The meteorological data were recorded at the IITA station. The variables were: daily rainfall accumulated over the trapping periods, i.e. the seven days intervals of trapping $(\mathrm{mm})$, the mean daily windspeed $(\mathrm{km} / \mathrm{h})$, the mean daily temperature $\left({ }^{\circ} \mathrm{C}\right)$, the mean daily relative humidity $(\%)$, and the accumulated evaporation during the seven days intervals of trapping.

Multiple regression models were used for the analysis of the effect of weather on flight activity of both insects (Sokal $\&$ Rohlf, 1992). The dependent variables were numbers of $P$. truncatus and T. nigrescens in the pheromone trap. Since trap catches of both exotic insects increased significantly in the course of the observation period, probably due to immigration from West to East as well as population growth, the year of trapping was included as an independent variable in the analysis. Considering that $T$. nigrescens also responds to the male-produced aggregation pheromone of $P$. truncatus, the trap data of $P$. truncatus were included as an independent variable in the analysis of the flight activity of the predator.

For all analyses, the trap data were normalized with the transformation $\log (x+1)$ prior to analysis. Means and standard errors were computed to investigate spatial effects on the trap results of $P$. truncatus and $T$. nigrescens, both for the Mono and IITA station data sets. In the case of the trap catches of $P$. truncatus on the IITA station the full data set was used, whereas for $T$. nigrescens only the data of 1994 and 1995.

\section{Results}

Figure 2 shows the results of the pheromone trap monitoring programme in Mono province, in relation to rainfall, and a diagram indicating the maize growing and storage seasons in this part of Benin. Two distinct peaks in the annual flight cycle of $P$. truncatus were observed: The first peak occured between the end of December and the beginning of January, followed by a more or less steady decline until April. From then on the flight activity rose again and reached a second peak between May and June. The lowest numbers of $P$. truncatus were recorded between September and October. The May-June peak in flight activity coincided with high precipitation during the main rainy season. However, the relationship between precipitation and flight activity of $P$. truncatus was not observed in the minor rainy season, between September and November. The largest trap catches were recorded approximately eight weeks before the harvest of the major season maize, i.e. during a period where the physiological state of the maize cobs does not permit an infestation of $P$. truncatus (Borgemeister, unpublished data). The December-January peak in flight activity coincided with the end of the short growing season and the beginning of the short storage season, respectively. In order to supply food for their families, most small-scale farmers in south-western Benin start to remove maize from their major season stores from November onwards. Most of these stores are emptied from December to February (Agbaka, 1996).

Trap catches of $T$. nigrescens were low at the end of 1993 in Mono province. In 1994 the numbers gradually increased from January until July, and from then on declined, until the end of observation in October. The highest $T$. nigrescens trap results were recorded approximately six weeks after the May-June peak of $P$. truncatus flight activity. The flight activity of $T$. nigrescens was considerably higher during the major rainy season than during the minor rainy season. No obvious relationship between the flight cycle of $T$. nigrescens and the maize growing and storage season could be observed.

Although the central part of Mono province is rather homogeneous regarding climate, landscape and agriculture (Agbaka, 1996), notable differences between locations and the trap catches were observed (table 1).

Figure 3 shows the flight curves of $P$. truncatus and $T$. nigrescens and the meteorological parameters recorded at the IITA station in Abomey-Calavi. The trap catches of both beetles notably increased during the years of trapping. Despite the relatively short distance between the three traps on the IITA station, the numbers of trapped P. truncatus and $T$. nigrescens varied considerably (table 1 ).

Using multiple regression models, only mean daily temperature and the year of trapping proved to have a significant effect on the flight activity of $P$. truncatus (table 2 ). 


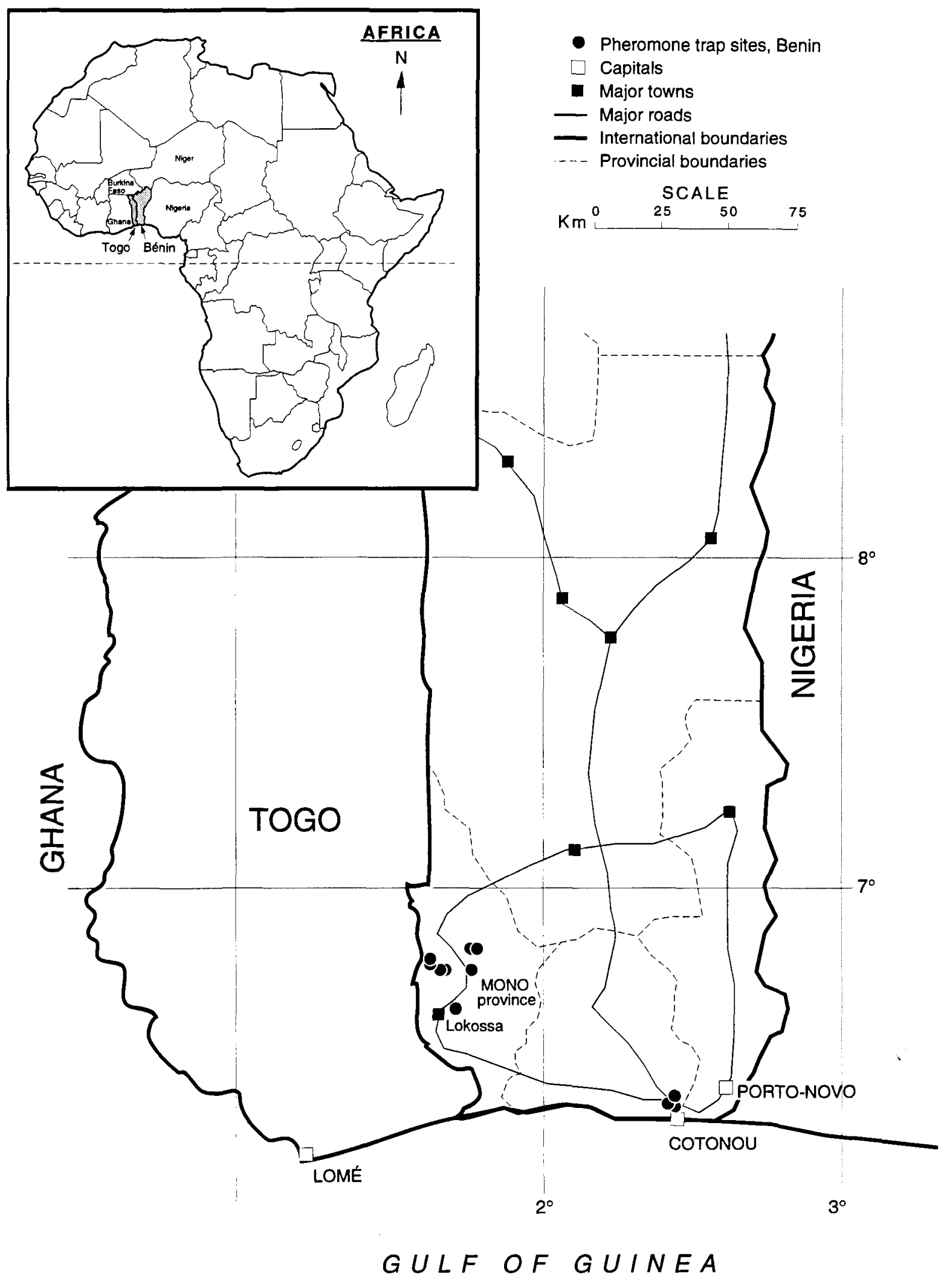

Fig. 1. Pheromone trap sites in the Mono province of south-western Benin and at the IITA station in Abomey-Calavi. 

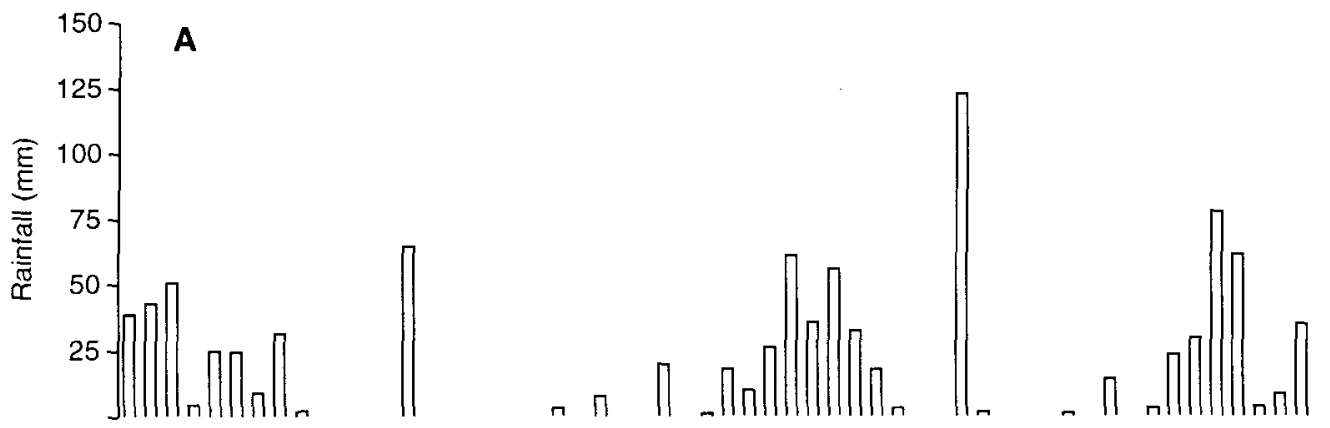

B
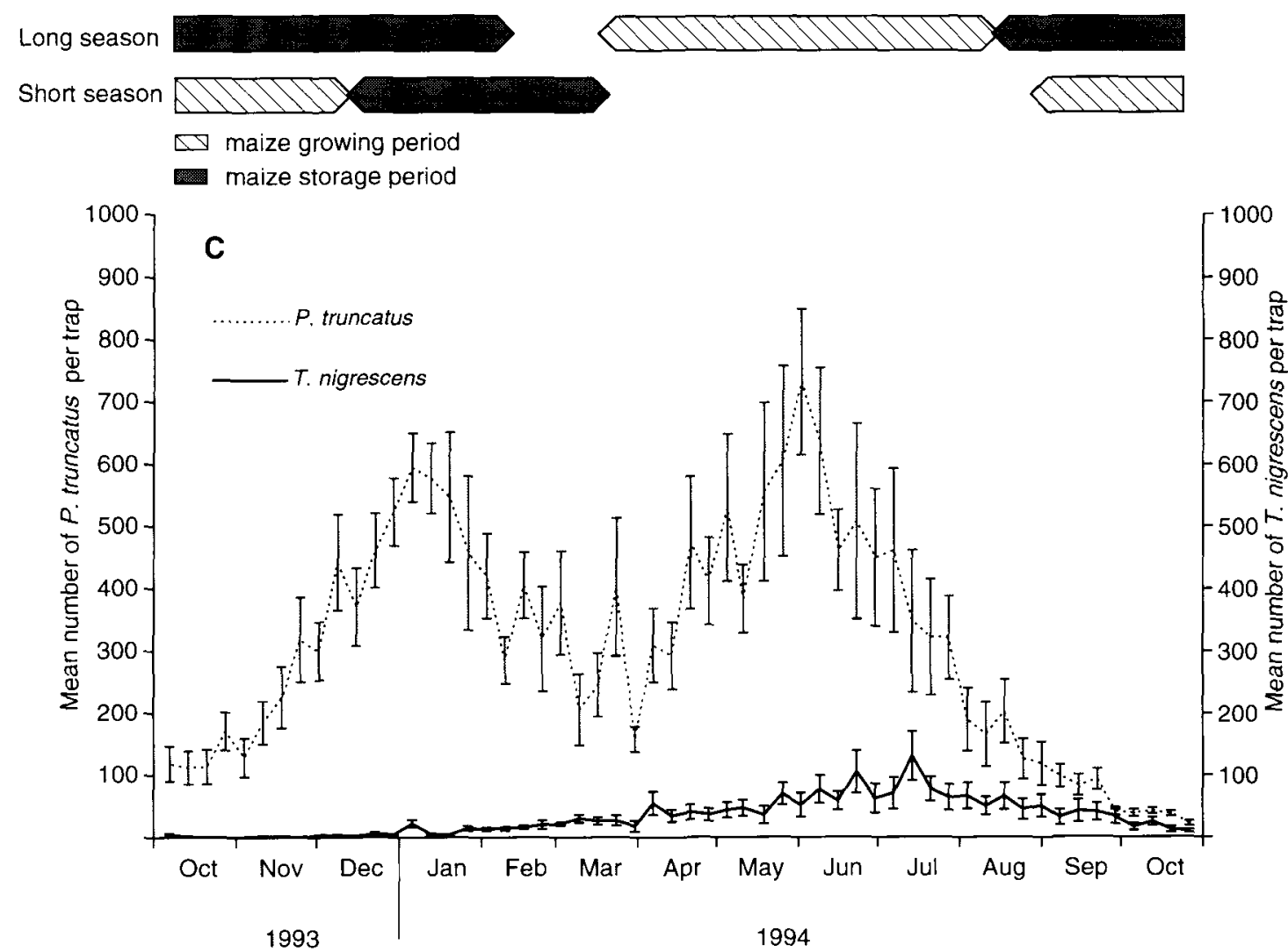

Fig. 2. Rainfall (A), maize production and storage cycle (B), and Prostephanus truncatus and Teretriosoma nigrescens pheromone trap catches (C) in the Mono province of south-western Benin between October 1993 to October 1994. Traps were examined weekly. Data points represent means of eight traps $( \pm \mathrm{SE})$.

Approximately $40 \%$ of the variance could be explained by these two variables, with the year of trapping contributing notably more to the model than the mean daily temperature. In the case of T. nigrescens in the model, $36 \%$ of the variance could be explained by the number of trapped P. truncatus, the rainfall data and the year of trapping (table 3). The independent variables, number of trapped $P$. truncatus and rainfall had higher standardized regression coefficients and therefore contributed more to the model than the years of trapping.

\section{Discussion}

Strong seasonality was observed in the flight activity of
$P$. truncatus and $T$. nigrescens in the Mono province of south-western Benin. Variable trap catches over the course of the year were also recorded by Tigar et al. (1994) in Mexico and Giles et al. (1995) in Kenya. In the Mono province, where $P$. truncatus has been present for more than eight years, and which constitutes one of the major maize growing regions in southern Benin (Anon., 1996), two peaks in flight activity were observed between January and February and between May and June, respectively. Similar bimodal peaks in flight activity were also noted by Wright et al. (1993) in their study in southern Togo. The December-January peak in the flight cycle of P. truncatus coincided with the harvest of the short growing season maize and the beginning of the minor storage season. Field studies in the Mono province revealed 
Table 1. Mean number (SE) of Prostephanus truncatus and Teretriosoma nigrescens caught in pheromone traps in Mono province of south-western Benin (data gathered in eight different locations between October 1993 and October 1994) and on the IITA station in Abomey Calavi (data gathered in three different locations, for $P$. truncatus between April 1992 and December 1995, and for T. nigrescens between January 1994 and December 1995).

\begin{tabular}{lccrc}
\hline & $\begin{array}{c}\text { P. truncatus } \\
\text { mean SE }\end{array}$ & $n$ & \multicolumn{2}{c}{ T. nigrescens } \\
& mean SE & $n$ \\
\hline Mono province & & & & \\
site 1 & $247.9 \pm 21.2$ & 55 & $34.9 \pm 4.7$ & 55 \\
site 2 & $264.3 \pm 24.5$ & 56 & $36.2 \pm 5.4$ & 56 \\
site 3 & $393.9 \pm 47.7$ & 53 & $71.7 \pm 9.8$ & 53 \\
site 4 & $335.6 \pm 35.8$ & 53 & $54.2 \pm 8.6$ & 53 \\
site 5 & $515.7 \pm 51.6$ & 55 & $28.1 \pm 5.2$ & 55 \\
site 6 & $260.8 \pm 21.8$ & 52 & $8.5 \pm 1.1$ & 52 \\
site 7 & $163.6 \pm 21.4$ & 55 & $20.2 \pm 3.0$ & 55 \\
site 8 & $318.0 \pm 30.8$ & 55 & $9.1 \pm 1.3$ & 55 \\
IITA station & & & & \\
site 1 & $198.4 \pm 20.6$ & 187 & $23.3 \pm 4.4$ & 104 \\
site 2 & $202.6 \pm 24.4$ & 187 & $0.9 \pm 0.2$ & 104 \\
site 3 & $174.3 \pm 19.1$ & 186 & $16.1 \pm 2.6$ & 104 \\
\hline
\end{tabular}

however, that infestation of maize in the minor storage season with $P$. truncatus was generally low compared to the corresponding major storage season (Borgemeister, unpublished data). However, the December-January peak in flight activity occurred at a time when $P$. truncatus densities were high in major season maize stores (Borgemeister et al., 1994). Studies on the dispersal behaviour of $P$. truncatus from maize cultures showed that at high densities approximately $30 \%$ of the P. truncatus population emigrates (Scholz et al., 1997) Furthermore, many farmers in the region start to remove maize from their long season stores from November onwards, and the majority of these stores are emptied between December and February (Agbaka, 1996). Recent studies on the gut content analysis of trapped $P$. truncatus indicated, that during the December-January peak in flight activity, the majority of $P$. truncatus contained starch in their stomachs, and therefore had presumably fed on maize or cassava prior to dispersion (Borgemeister, unpublished data). This suggests, that the December-January peak was to some extent associated with maize storage, resulting from beetles that emigrated from grain stores.

There was no obvious relationship between the May and June peak in flight activity of $P$. truncatus and the availability of maize as a host in Benin. Prostephanus truncatus tended to fly in high numbers when the physiological state of the maize cobs in the field did not permit an infestation by the beetle i.e. when the maize was still in a vegetative or early cob initiation phase. Previous research has shown that $P$. truncatus can only survive on maize cobs shortly before their physiological maturity and cannot reproduce on them until the moisture content falls to below 30\% (Borgemeister unpublished data). Moreover, the flight activity of $P$. truncatus decreased sharply towards the harvest time of the maize crops and the beginning of the major storage season. Flight activity was at its lowest level approximately two to three months after stacking, a time when individuals of $P$. truncatus were first being recorded in a storage experiment carried out in the same region (Borgemeister et al., 1994). Results were consistent with Ríos Ibarra (1991) in Mexico and Novillo Rameix (1991) in Honduras, who also found no relationship between the flight activity of $P$. truncatus and the maturity of maize in the field or the harvest of the crop.

No clear relationship between the flight activity of $T$. nigrescens and the maize growing seasons and/or the storage periods could be detected. The flight cycle of the predator showed only one peak, approximately six weeks after the major peak of $P$. truncatus. Assuming that the increased flight activity of $P$. truncatus is at least partially related to adult beetles leaving habitats due to a decreasing nutritive value of the substrate and/or crowding, as shown in recent experiments (Scholz et al., 1997), the predators might react with time delayed emigration. However, experiments on the functional and numerical response of $T$. nigrescens to test this hypothesis are currently under way.

Consistent differences in levels of catches between trap sites in Mono province and on the IITA station were detected for both insects. In their study in Mexico, Tigar et al. (1994) also observed a strong effect of location on trap catches of $P$. truncatus and T. nigrescens, and attempts to map the presence of $P$. truncatus in Togo revealed large differences among neighbouring trap sites (Richter \& Biliwa, 1991)

Trap catches of $P$. truncatus and T. nigrescens at the IITA station increased during the period of observation, probably because both insects were still rising in numbers in the eastern part of southern Benin, following immigration from the initial focus of infestation in Togo to the west.

Flight activity of both $P$. trincatus and $T$. nigrescens was elevated during the major rainy season in the Mono province. However, no clear response was observed in the minor rainy season. Thus, the more detailed regression analysis revealed no effect of precipitation or relative humidity on P. truncatus, but a positive effect of mean daily temperature. In contrast, $T$. nigrescens flight activity was positively correlated with rainfall. Tigar et al. (1993) observed that $P$. truncatus flies only at dawn and dusk, whereas the main flight activity of $T$. nigrescens is around noon. Hence, the responses of the two beetle species to weather factors might be due to their different diurnal flight activity. One year of monitoring of flight traps in Mexico (Ríos Ibarra, 1991), and over two years in Honduras (Novillo Rameix, 1991) suggested that $P$. truncatus captures were closely correlated with rainfall, with much reduced flight activity in the winter and dry season, respectively. In a more recent analysis using five years of trapping data recorded on the campus of the Escuela Agrícola Panamericana at Zamorano, Honduras, no clear associations between flight activities of either $P$. truncatus or $T$, nigrescens with precipitation or relative humidity could be observed ( $R$. Espinal \& R. Markham, unpublished data). However, higher numbers of T. nigrescens in pheromone traps and in store samples were recorded in the more humid tropical regions of Honduras ( $R$. Espinal, personal communication). Tigar et al . (1994) noted a close relationship between rainfall pattern and $P$. truncatus flight activity in the drier and / or temperate zones of Mexico and a less clear relationship with rainfall in the humid tropical zones. Giles et al. (1995) observed a strong increase in flight activity of $P$. truncatus during the minor rainy season in a dryland deciduous forest area in Kenya, but a much weaker response during the major rains.

However, results from pheromone traps have to be interpreted carefully, since they may be influenced by varying biotic and abiotic factors. The age and mating status of the insects, the presence of varying numbers of conspecific pheromone sources, fluctuations in the availability of host 

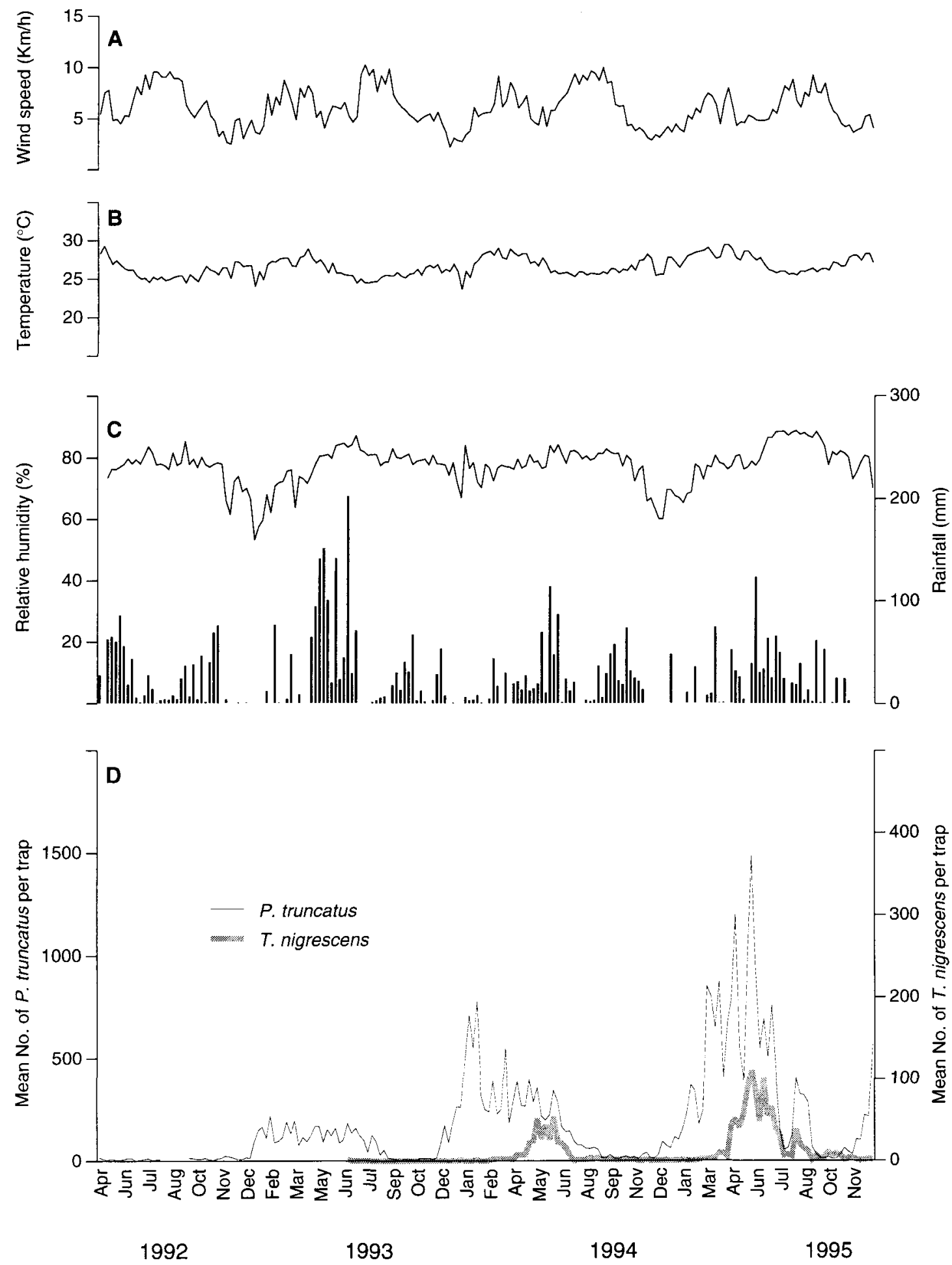

Fig. 3. Wind speed (A), temperature (B), relative humidity and rainfall (C) at the IITA station in Abomey-Calavi. Data points are the mean (wind speed, temperature, relative humidity) and accumulated (rainfall) values during the respective trapping period. D: Prostephanus truncatus and Teretriosoma nigrescens pheromone trap catches at the IITA station in Abomey-Calavi from April 1992 to December 1995. Traps were examined weekly. Data points represent mean of three traps. 
Table 2. Multiple regression analysis for assessing the impact of meteorological factors on the numbers of trapped Prostephanus truncatus. Data from three pheromone traps collected in weekly intervals at the IITA station in Abomey-Calavi, Benin, between April 1992 until December 1995.

\begin{tabular}{lcc}
\hline Variable & \multicolumn{2}{c}{ Regression statistics } \\
\cline { 2 - 3 } & $b$ & $t$ \\
\hline Dependent variable & & \\
$\quad P$. truncatus $[\log (x+1)]$ & & \\
Independent variables & 0.55 & $8.96^{*}$ \\
year of trapping & 0.18 & $2.87^{*}$ \\
mean daily temperature & \\
\hline
\end{tabular}

Intercept $=-1.77$, explained variance $R^{2}=0.395 ; b$ is the standardized regression coefficient; $t$ is the $t$ statistics; *means significant at $P<0.05$.

plants, and also daylength, wind speed, temperature and relative humidity can affect trap results (McNeil, 1991). Pheromone release rates and the attraction range of a pheromone trap may vary with temperature and wind speed (Elkington \& Cardé, 1984). Nothing is known about the effect of temperature on the evaporation of the synthetic pheromone of $P$. truncatus. However, in our study we did not detect any effect of wind speed on trap catches, and temperature was positively related only to the flight activity of $P$. truncatus. Mating status does not influence the response of $P$. truncatus to the pheromone and only old beetles show slightly reduced response rates (Fadamiro, 1995). Sex ratios among $P$. truncatus trapped in pheromone traps varied little during the course of the year (D. Scholz, unpublished data) In addition, recent electroantennogram studies revealed that both $P$. truncatus and $T$. nigrescens have approximately the same reception threshold for the two components of the $P$. truncatus produced pheromone (D. Scholz, unpublished data). Therefore, the observed seasonal variations in trap catches are more likely to reflect fluctuations in the flight activity of the two beetles, than behaviourally-triggered responses to the pheromone or abiotic affects on the synthetic pheromone itself.

Since $P$. truncatus belongs to a family of wood-boring insects and has been found in a wide variety of different habitats, including forests (Rees et al., 1990; Ríos Ibarra, 1991), it has been suggested that $P$. truncatus is more of a forest-inhabiting insect that sometimes attacks stored maize

Table 3. Multiple regression analysis for assessing the impact of meteorological and biotic factors on the numbers of trapped Teretriosonta nigrescens. Data from three pheromone traps collected in weekly intervals at the IITA station in AbomeyCalavi, Benin, between January 1994 until December 1995.

\begin{tabular}{|c|c|c|}
\hline \multirow[t]{2}{*}{ Variable } & \multicolumn{2}{|c|}{ Regression statistics } \\
\hline & $b$ & $t$ \\
\hline $\begin{array}{l}\text { Dependent variable } \\
T \text {. nigrescens }[\log (x+1)]\end{array}$ & & \\
\hline $\begin{array}{l}\text { Independent variables } \\
\text { accumulated rainfall during the }\end{array}$ & & \\
\hline trapping period & 0.38 & $4.76^{*}$ \\
\hline P. truncatus [in $\log (x+1)]$ & 0.35 & $4.33^{*}$ \\
\hline year of trapping & 0.21 & $2.65^{*}$ \\
\hline
\end{tabular}

Intercept $=-0.59$, explained variance $R^{2}=0.36 ; b$ is the standardized regression coefficient; $t$ is the $t$ statistics; ${ }^{*}$ means significant at $P<0.05$. or cassava than the reverse (Markham et al., 1991) - a proposition is supported by recent laboratory experiments (Nang'ayo et al., 1993) and field studies (Ramírez-Martínez et al., 1994). Giles et al. (1995) concluded that the close association of flight activity in Kenya with the minor rainy season is probably more related to the availability of natural host plants than a straightforward relationship of dispersion with meteorological factors. For the humid coastal area of Benin this could mean that the first peak in flight activity of $P$. truncatus is more related to storage practice, whereas the major peak reflects the search pattern of the beetle for its natural woody host plants.

\section{Acknowledgements}

We thank $\mathrm{Mr} \mathrm{H}$. Schneider, Mr R. Oussou and Dr F Schulthess for most helpful criticism of the manuscript. Ms I. Olaleye provided figure 1 . Special thanks to Dr P. Neuenschwander, Director of the Plant Health Management Division of the International Institute of Tropical Agriculture, Benin, for continuing support for our work. The work was conducted within the framework of projects supported by the German Ministry for Economic Cooperation and Development (BMZ) and the Danish International Development Agency (DANIDA).

\section{References}

Adda, C., Borgemeister, C., Meikle, W.G., Markham, R.H. Olaleye, I., Abdou, K.S. \& Zakari, M.O. (1996) First record of the larger grain borer, Prostephanus truncatus (Horn) (Coleoptera: Bostrichidae), in the Republic of Niger. Bulletin of Entomological Research 86, 83-85.

Agbaka, A. (1996) Etude biologique et possibilité de lutte integrée contre Prostephanus truncatus (Horn) (Coleoptera: Bostrichidae) razageurs des stocks de mais dans les milienx paysans en Répubique du Bénin. PhD thesis, Université Nationale de Côte d'Ivoire, xvi + $145 \mathrm{pp}$.

Anon. (1992) Rapport annuel 1992. Service Protection des Végétaux et du Contrôle Phytosanitaire. Porto Novo, République du Bénin, 63 pp.

Anon. (1996) Rapport d'évaluation de la campagne agricole 1995/1996 et les perspectives alimentaires pour 1996 an Benin. Ministère du Développement Rural, Office National d'Appui à la Sécurité Alimentaire et Projet GTZ N" 92.2115.1, Cotonou, Benin, 192 pp

Anon. [authors: S. Krall \& F. Favi; omitted in error in original] (1986) Benin. Further distribution of the larger grain borer (Prostephanus truncatus) in West Africa. FAO Plant Protection Bulletin 34, 213-214.

Biliwa, A., Boeye, J., Fischer, H.U. \& Helbig, J. (1992) Stratégie de lâchers et études de suivi de Teretriosonta nigrescens au Togo. pp. 138-142 in Boeye, J., Wright, M. \& Laborius, G.A. (Eds) Implenentation of and further research on biological control of the larger grain borer. Proceedings of an FAO/GTZ Coordination Meeting. Food and Agriculture Organisation of the United Nations and Deutsche Gesellschaft für Technische Zusammenarbeit (GTZ) GmbH.

Boeye, J. (1988) Autökologische Untersuchungen zum Verhalten des grossen Kornbohrers Prostephanus truncatus (Horn) (Coleoptera; Bostrichidae) in Costa Rica (Autecological investigations on the behaviour of the larger grain borer Prostephanus truncatus (Horn) (Coleoptera: Bostrichidae) in Costa Rical. PhD thesis, Christian-Albrechts-University Kiel, Germany, xiii +195 pp 
Borgemeister, C., Adda, C., Djomamou, B., Degbey, P., Agbaka, A., Djossou, F., Meikle, W.G. \& Markham, R.H. (1994) The effect of maize cob selection and the impact of field infestation on stored maize losses by the larger grain borer (Prostephanus truncatus (Horn) Col., Bostrichidae) and associated storage pests. pp. 906-904 in Highley, E., Wright, E.J., Banks, H.J. \& Champ, B.R. (Eds) Stored product protection. Proceedings of the 6th International Working Conference on Stored-product Protection. CAB International, Wallingford, UK.

Compton, J.A.F. \& Ofosu, A. (1994) Biological control of the larger grain borer with Teretriosoma nigrescens. pp. 1-8 in Compton, J.A.F. (Ed.) Sixth Quarterly Report, Ghana Larger Grain Borer Project (Research Programme - Volta Region). Ghana Ministry of Food and Agriculture/UK Overseas Development Administration.

Dendy, J., Dobie, P., Saidi, J.A., Smith, J.L. \& Uronu, B. (1989) Trapping the larger grain borer Prostephantus truncatus in maize fields using synthetic pheromones. Entomologia Experimentalis et Applicata 50, 241-244.

Dunstan, W.R. \& Magazini, I.A. (1981) Outbreaks and new records. Tanzania. The larger grain borer on stored products. FAO Plant Protection Bulletin 29, 80-81.

Elkinton, J.S. \& Cardé, R.T. (1984) Odor dispersion. pp. 73-94 in Bell, W.J. \& Cardé, R.T. (Eds) Chemical ecology of insects. London, New York, Chapman and Hall.

Fadamiro, H.Y. (1995) Flight behaviour and pheromone communication of the larger grain borer, Prostephanus truncatus (Horn) (Coleoptera: Bostrichidae). PhD thesis, Green College, Oxford, UK, vii + 186 pp.

Farrell, G. (1990) An investigation of the flight behaviour of the larger grain borer Prostephanus truncatus (Horn) (Coleoptera: Bostrichidae) in response to synthetic pheromone. MSc thesis, University of Birmingham, UK, iv $+50 \mathrm{pp}$.

Farrell, G. \& Key, G.E. (1992) Flight behaviour of the larger grain borer Prostephanus truncatus in response to synthetic pheromone. Tropical Science 32, 163-170.

Giles, P., Hill, G., Nang'ayo, F., Farrell, G., Stabrawa, A. \& Wekesa, P. (1995) Entomological and socio-economic investigations for the development of integrated pest management strategies against Prostephanus truncatus. Kenya Agriculture Research Institute (KARI), Nairobi, Kenya and Natural Resources Institute (NRI), Chatham Maritime, UK, $\mathrm{xxiv}+273 \mathrm{pp}$.

Haines, C.P. (1981) Insects and arachnids from stored products: A report on specimens received by the Tropical Stored Products Centre 1973-1977. Report of the Tropical Products Institute, L54, $73 \mathrm{pp}$.

Harnisch, R. \& Krall, S. (1984) Togo: Further distribution of the larger grain borer in Africa. FAO Plant Protection Bulletin 32, $113-114$.

Hodges, R.J. (1994) Recent advances in the biology and control of Prostephanus truncatus (Coleoptera: Bostrichidae). pp. 929-934 in Highley, E., Wright, E.J., Banks, H.J. \& Champ, B.R. (Eds) Stored product protection. Proceedings of the 6th International Working Conference on Stored-product Protection. CAB International, Wallingford, UK.

Hodges, R.J., Cork, A. \& Hall, D.R. (1984) Aggregation pheromones for monitoring the greater grain borer, Prostephanus truncatus. British Crop Protection Conference Pests and Diseases 4A-3, 255-259.

Markham, R.H., Wright, V.F. \& Ríos Ibarra, R.M. (1991) A selective review of research on Prostephanus truncatus (Col.: Bostrichidae) with an annotated and updated bibliography. Ceiba 32, 1-90.

Nang'ayo, F.L.O., Hill, M.G., Chandi, E.A., Chiro, C.T., Nzeve, D.N. \& Obiero, J. (1993) The natural environment as a reservoir for the larger grain borer Prostephamus truncatus (Horn) (Coleoptera: Bostrichidae) in Kenya. African Crop Science Journal 1, 39-47.

McNeil, J.N. (1991) Behavioral ecology of the pheromone-mediated communication in moths and its importance in the use of pheromone traps. Anmual Review of Entomology 36, $407-430$.

Novillo Rameix, P. (1991) Prostephanus truncatus (Horn) (Coleoptera: Bostrichidne) en el ambiente de almacenamiento tradicional de naiz en el Valle de El Zamorano, Honduras, C.A. [Prostephanus truncatus (Horn) (Coleoptera: Bostrichidae) in the traditional maize storage environment in the El Zamorano Valley, Honduras, Central America]. Tesis de Ingeniero Agrónomo, Escuela Agrícola Panamericana, Honduras, viii $+129 \mathrm{pp}$.

Ramírez-Martínez, M., de Alba-Avila, A. \& Ramírez-Zurbía, R. (1994) Discovery of the larger grain borer in a tropical deciduous forest in Mexico. Journal of Applied Entonology 118, 354-360.

Rees, D.P., Rodriguez Rivera, R. \& Herrera Rodriguez, F.J. (1990) Observations of the ecology of Teretriosoma nigrescens Lewis (Col.: Histeridae) and its prey Prostephantus truncatus (Horn) (Col:: Bostrichidae) in the Yucatan peninsula, Mexico. Tropical Science 30, 153-165.

Richter, J. \& Biliwa, A. (1991) Landesweite Erhebung mittels Pheromonfallen zur Verbreitung von Prostephanus truncatus (Horn) (Col., Bostrichidae) in Togo. [Country-wide pheromone trap monitoring for Prostephantis truncatus (Horn) (Col., Bostrichidae) in Togo]. Anzeiger Schädlingskunde, Pflanzenschutz, Umweltschutz 64, 89-92.

Ríos Ibarra, R.M. (1991) Ecologia de Prostephanus truncatus (Horn) (Coleoptera: Bostrichidae) en el altiplano mexicano [Ecology of Prostephanus truncatus (Horn) (Coleoptera: Bostrichidae) on the Mexican platean]. Tesis de Maestro en Ciencias, Colegio de Postgraduados, Montecillo, México, $\mathrm{v}+85 \mathrm{pp}$.

Scholz, D., Borgemeister, C., Markham, R.H. \& Poehling, H.-M. (1997) Flight initiation in Prostephanus truncatus: Influence of population density and aggregation pheromone. Entomologia Experimentalis et Applicata (in press).

Sokal, R.R. \& Rohlf, F.J. (1992) Biontetry. 2nd edn. 859 pp. New York, W.H. Freeman \& Company.

Tigar, B.J., Key, G.E., Flores-S., M.E. \& Vazquez-A., M. (1993) Flight periodicity of Prosteplanus truncaturs and longevity of attraction to synthetic pheromone. Entomologia Experimentalis et Applicata 66, 91-97.

Tigar, B.J., Osborne, P.E., Key, G.E., Flores-S., M.E. \& Vazquez-A., M. (1994) Distribution and abundance of Prostephanus truncatus (Coleoptera: Bostrichidae) and its predator Teretriosonta nigrescens (Coleoptera: Histeridae) in Mexico. Bulletin of Entomological Researcl 84, 555-565.

Wright, M., Akou-Edi, D. \& Stabrawa, A. (1993) Larger Grain Borer Project, Togo. Infestation of dried cassava and maize by Prostephanus truncatus: entomological and socio-economic assessments for the development of loss reduction strategies. Natural Resources Institute (NRI) Report R1941, Chatham Maritime, UK, xi + 141 pp.

(Accepted 24 October 1996) (c. CAB INTERNATIONAL, 1997 